\title{
Identical twins with Pierre Robin syndrome; unusual encounter
}

Nabil Shdaifat, Zaid al-Zoubi, Hazem Khraisat, Rana Al-Omor, Khaled Matar

Dentistry Department, Jordanian Royal Medical Services, Jordan

Type of article: Case report

\begin{abstract}
New born babies could suffer from multiple craniofacial abnormalities, such as Pierre Robin syndrome, which consists of micrognathia and relative macroglossia with or without cleft palate. Although Pierre Robin syndrome is well described in literature, only a few have mentioned its occurrence in identical twins. This paper presents a rare incident of full-term twin babies born with the sequence of Pierre Robin syndrome, which consists of micrognathia, cleft palate, and glossoptosis. Although it is a rare coincidence, Pierre Robin syndrome still can occur in identical twin babies. The treatment is a step-by-step approach, but all procedures are mainly directed to widening the pharyngeal space.
\end{abstract}

Keywords: Cleft palate, Macroglssia, Micrognathia, Pierre Robin

\section{Introduction}

Although Pierre Robin described this clinical entity in 1923 and then described the full triad to include cleft palate in 1934 (1), the clinical components of this sequence were described by Von Siebold in 1835, and it was Fairbairn who mentioned the full triad in 1846 (2). Butow and his colleagues had reviewed the literature and recommended that Pierre Robin syndrome (PRS) should be subdivided into Fairbairn-Robin triad and Siebold-Robin sequence (3). Pierre Robin syndrome is a sequence; its three main features are retrognathia, cleft palate, and glossoptosis. Breathing and feeding difficulties that result from these anomalies might require emergency management (4). The exact cause is not known, but it could be present at birth as a part of many genetic syndromes. External factors that interfere with the growth of the lower jaw may contribute to PRS. Some neurological conditions can decrease the jaw movement in utero restricting its growth, such as Stickler syndrome and Nager syndrome. These patients could be diagnosed before birth with the help of ultrasonography or immediately after birth. They undergo multiple surgeries under general anesthesia. Pierre Robin syndrome incidence in identical twins is rare but still occur. In this paper, we will present a case report of a rare incident of full-term identical twin babies born with the full sequence of Pierre Robin syndrome.

\section{Case Presentation}

\subsection{History}

Full-term identical twin baby boys delivered by cesarean section after noneventful pregnancy. Birth weights were $2,100 \mathrm{~g}$ and 2,400g. Apgar score at birth was 7/10, and at $5 \mathrm{~min}$ was 8/10. Formal consultation was sent to our team in Prince Hashem bin Al-Hussein Military Hospital-Zarqa city/Jordan on 20 July 2016 by pediatrician; neonates were diagnosed to have Pierre Robin syndrome, for further evaluation and management.

\subsection{Clinical Examination}

Upon extraoral clinical examination, both neonate showed mandibular retrognathia, a characteristic bird-face appearance (Figure 1). Intraoral examination revealed glossoptosis, palatal malformations, and cleft palate. Family history of the patients revealed no similar cases, and there was no history of cleft palate or facial anomalies in the family (Figure 2).

\section{Corresponding author:}

Dr. Nabil Shdaifat, Dentistry Department, Jordanian Royal Medical Services, Jordan.

Tel.: +962 777742722, E-mail: Nabilshdaifat 2020@gmail.com

Received: February 30, 2017, Accepted: May 03, 2017, Published: May 2017

iThenticate screening: April 27, 2017, English editing: May 10, 2017, Quality control: May 14, 2017

(C) 2017 The Authors. This is an open access article under the terms of the Creative Commons Attribution-NonCommercialNoDerivs License, which permits use and distribution in any medium, provided the original work is properly cited, the use is non-commercial and no modifications or adaptations are made. 


\subsection{Investigations}

For both infants, the full blood count and kidney function tests were within the normal range; 2D echo revealed patent foramen ovale, brain ultrasound showed no abnormalities, and renal ultrasound showed no abnormality.
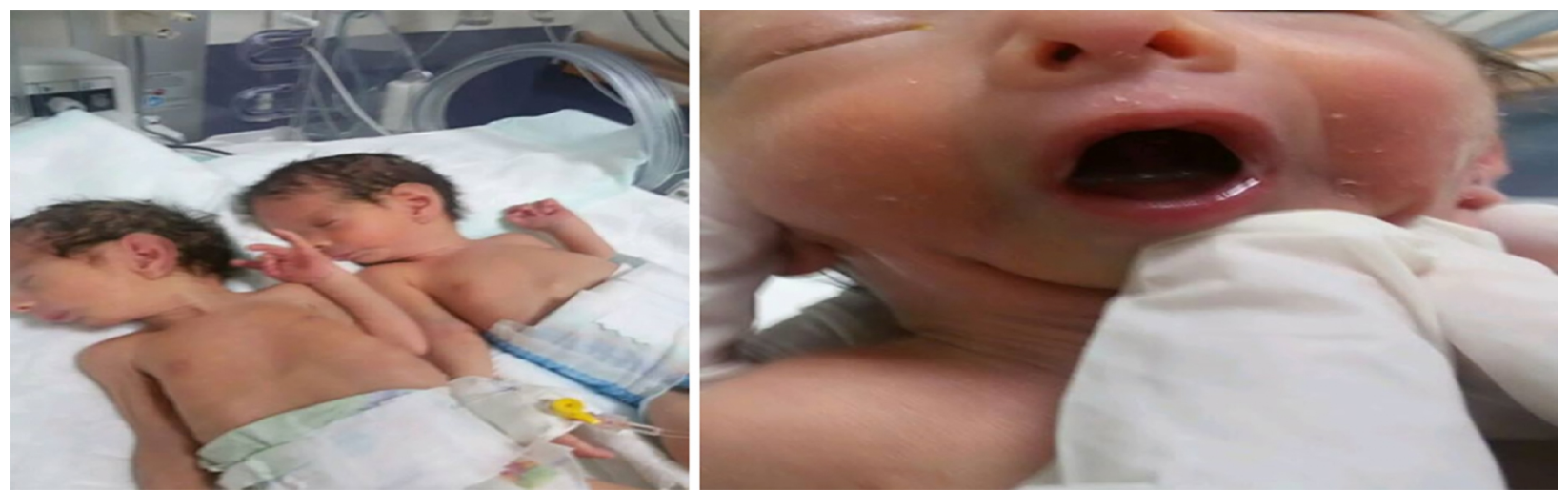

Figure 1. Identical twins presented with PRS.

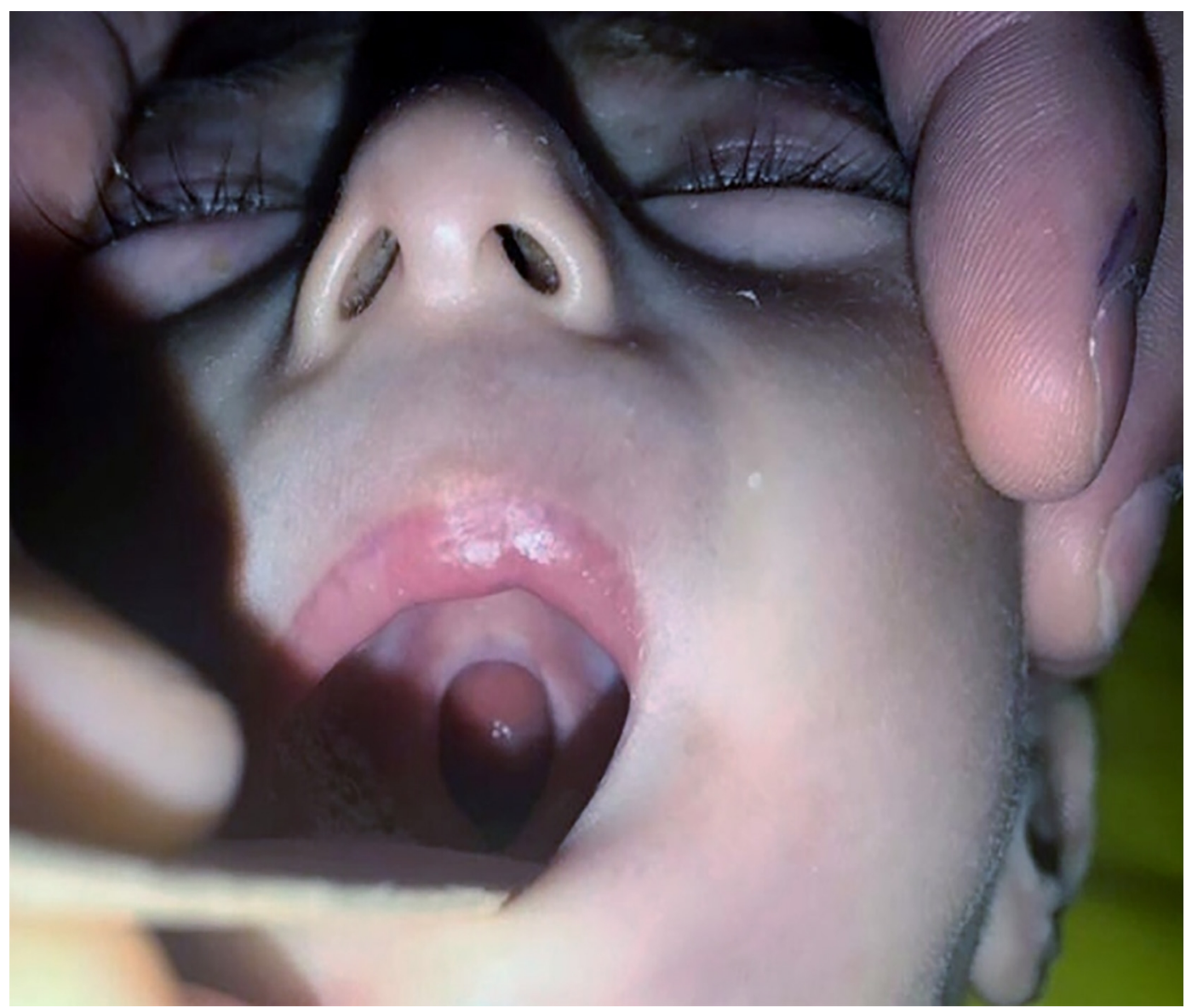

Figure 2. Photo of neonate at age of six weeks showing cleft palate.

\section{Discussion}

Pierre Robin syndrome is a craniofacial anomaly comprising mandibular hypoplasia, cleft of the secondary palate and glossoptosis, which might lead to a life-threatening obstructive apnea and feeding difficulties during neonatal period. It is reported that Pierre Robin syndrome has an incidence that ranges between 1/8500 and 1/14,000 births $(5,6)$. The incidence of twins with PRS support a genetic theory as a cause; also supporting this theory is the higher 
incidence of cleft lip and palate in family members (7). Identical twin brothers' cases suffering from PRS are very rare; the literature reported that Sachtleben described two brothers who suffered from PRS symptoms, which were associated with other congenital anomalies (8). Shah et al. also had described PRS in four siblings, which included a set of twins (9). Smith and Stowe reported affected brothers in 1961 (10), and a year later patients were pictured by McKusick who raised the possibility that these brothers might had either Stickler syndrome or Wagner syndrome (11). Others argued that Stickler syndrome should be considered first in cases of the Pierre Robin syndrome, especially in familial incidences (12). Management of infants with PRS is focused mainly with functional issues associated with airway and feeding. Thirty percent mortality has been mention, but the prognosis is good if the neonate survive the respiratory and feeding issues (13). Thus, treatment may be as a surgical emergency in the neonatal period to the symptomatic management of upper respiratory obstruction and feeding problems. All procedures are mainly directed to widening the pharyngeal space or bridging the narrow upper airway; these range from postural positioning to use of appliances to surgical procedures (14). Our plan in management of such cases is a step-by-step approach as follows: On day one, a tongue tie was done with lingual mucosa (glossopexy) to facilitate soft nipple feeding with wide opening or squeeze bottle (15). Palatal feeding obturator temporary constructed for both twins until surgical treatment is initiated to close the cleft palate for the purpose of ease of feeding and to prevent regurgitation or aspiration and to correct tongue positioning and speech development and reduce the incidence of nasopharyngeal infections (16). An 18-month surgical procedure using the von Langenbeck technique, including iliac crest bone graft, will be done to close the palatal cleft (17). At the moment, both babies are growing well, and their mandibular growth is under observation. We are planning an orthodontic approached treatment at the mixed dentition stage between 9 to 11 years to expand the palate and advance the mandible to stimulate its growth (18). Surgical treatment after the child turns 18 years old includes orthognathic surgery and mandibular distraction osteogenesis (19).

\section{Conclusions}

Although it is a rare coincident Pierre Robin syndrome still can occur in identical twin babies. The treatment is a step-by-step approach, but all procedures are mainly directed to widening the pharyngeal space.

\section{Acknowledgments:}

Authors disclose no funding sources. The authors thank Dr. Yahia Draidi, Msc in Periodontics-Jordanian Royal Medical Services and Yousef Shmailan, Msc in Prosthodontics-Jordanian Royal Medical Services who provided insight, which greatly assisted the research.

\section{Conflict of Interest:}

There is no conflict of interest to be declared.

\section{Authors' contributions:}

NS is responsible for the concept of the case report. NS and KM wrote the manuscript. ZZ, HK, and RO reviewed and edited the manuscript. NS and KM reviewed references. All authors read and approved the final manuscript.

\section{References:}

1) Robin P. La glossoptose. Son diagnostic, ses conséquences, son traitement. Bull Acad Natl Med. 1923; 89: 37-41.

2) Von Siebold E. Micrognathia with breathing problems. Siebold's J (Gttingen) 1835: XV; 18.

3) Bütow KW, Zwahlen RA, Morkel JA, Naidoo S. Pierre Robin sequence: Subdivision, data, theories, and treatment - Part 1: History, subdivisions, and data. Ann Maxillofac Surg. 2016; 6(1): 31-4. doi: 10.4103/2231-0746.186133. PMID: 27563603, PMCID: PMC4979338.

4) Takeshita S, Ueda H, Goto T, Muto D, Kakita H, Oshima K, et al. Case report of Pierre Robin sequence with severe upper airway obstruction who was rescued by fiberoptic nasotracheal intubation. BMC Anesthesiol. 2017; 17(1): 43. doi: 10.1186/s12871-017-0336-0. PMID: 28288578, PMCID: PMC5348775.

5) Izumi K, Konczal LL, Mitchell AL, Jones MC. Underlying genetic diagnosis of Pierre Robin sequence: retrospective chart review at two children's hospitals and a systematic literature review. J Pediatr. 2012; 160(4): 645-50. doi: 10.1016/j.jpeds.2011.09.021. PMID: 22048048.

6) Tan TY, Kilpatrick N, Farlie PG. Developmental and genetic perspectives on Pierre Robin sequence. Am J Med Genet C Semin Med Genet. 2013; 163C(4): 295-305. doi: 10.1002/ajmg.c.31374. PMID: 24127256. 
7) Jakobsen LP, Knudsen MA, Lespinasse J, García Ayuso C, Ramos C, Fryns JP, et al. The genetic basis of the Pierre Robin sequence. Cleft Palate Craniofac J. 2006; 43(2): 155-9. doi: 10.1597/05-008.1. PMID: 16526920.

8) SACHTLEBEN P. [ON THE PATHOGENESIS AND THERAPY OF PIERRE ROBIN SYNDROME]. Arch Kinderheilkd. 1964; 171: 55-63. PMID: 14293686.

9) Shah CV, Pruzansky S, Harris WS. Cardiac malformations with facial clefts: with observations on the Pierre Robin syndrome. Am J Dis Child. 1970; 119(3): 238-44. doi: 10.1001/archpedi.1970.02100050240010. PMID: 5414813.

10) Jones KL. Smith's Recognizable Patterns of Human Malformation. 5th ed. Philadelphia: W.B. Saunders; 1970: 234-5.

11) McKusick VA, Abbey H, Bowen P, Boyer SH, Cohen BH, Danks DM, et al. Medical genetics 1961. J Chronic Dis. 1962; 15(5): 417-572. doi: 10.1016/0021-9681(62)90001-2.

12) Opitz JM. Personal Communication. Madison, Wis. 1973.

13) Shprintzen RJ, Siegel-Sadewitz VL, Amato J, Goldberg RB, Opitz JM, Reynolds JF. Anomalies associated with cleft lip, cleft palate, or both. Am J Med Genet. 1985; 20(4): 585-95. doi: 10.1002/ajmg.1320200404.

14) Andrews S, Sam M, Krishnan R, Ramesh M, Kunjappan SM. Surgical management of a large cleft palate in a Pierre Robin sequence: A case report and review of literature. J Pharm Bioallied Sci. 2015; 7(Suppl 2): S718-20. doi: 10.4103/0975-7406.163498. PMID: 26538951, PMCID: PMC4606693.

15) OECONOMOPOULOS CT. The value of glossopexy in Pierre-Robin syndrome. N Engl J Med. 1960; 262 : 1267-8. doi: 10.1056/NEJM196006232622504. PMID: 14428307.

16) Hegde RJ, Mathrawala NR. Pierre Robin sequence: report of two cases. J Indian Soc Pedod Prev Dent. 2010, 28(4): 326-30. doi: 10.4103/0970-4388.76170. PMID: 21273727.

17) Laine J, Vähätalo K, Peltola J, Tammisalo T, Happonen RP. Rehabilitation of patients with congenital unrepaired cleft palate defects using free iliac crest bone grafts and dental implants. Int J Oral Maxillofac Implants. 2002; 17(4): 573-80. PMID: 12182301.

18) Figueroa AA, Glupker TJ, Fitz MG, BeGole EA. Mandible, tongue, and airway in Pierre Robin sequence: a longitudinal cephalometric study. Cleft Palate Craniofac J. 1991; 28(4): 425-34. doi: 10.1597/15451569(1991)028<0425:MTAAIP>2.3.CO;2. PMID: 1742314.

19) Monasterio FO, Drucker M, Molina F, Ysunza A. Distraction osteogenesis in Pierre Robin sequence and related respiratory problems in children. J Craniofac Surg. 2002; 13(1): 79-83. doi: 10.1097/00001665200201000-00018. PMID: 11886999. 